\title{
A Happier and Less Sinister Past, a More Hedonistic and Less Fatalistic Present and a more Structured Future: Time Perspective and Well-Being
}

Background: Previous studies have established a link between how people relate to their past, present, and future (i.e., time perspective) and subjective well-being (i.e., life satisfaction, positive and negative affect). Time perspective comprises five dimensions: Past Positive, Past Negative, Present Hedonistic, Present Fatalistic, and Future. Life satisfaction can also be evaluated in relation to different time frames. Moreover, approach related positive affect is associated to a different concept of well-being labeled psychological wellbeing. In the present study we extend previous findings by investigating the effect of time perspective on the time frame of evaluations of life satisfaction (past, present, future) and by investigating the relationship between time perspective and psychological well-being.

Method: Questionnaires on time perspective (Zimbardo's Time Perspective Inventory), temporal life satisfaction (Temporal Satisfaction with Life Scale), affect (Positive Affect and Negative Affect Schedule), and psychological well-being (Scales of Psychological Well-Being - short version) were answered by 453 individuals. Two different structural equation models were tested, one of the relationship between time perspective and temporal life satisfaction, and the other of the relationship between time perspective, affect and psychological wellbeing.

Results: Time perspective affected life satisfaction depending on the time scale on which it was evaluated-memory of a negative past influenced life satisfaction in all time frames, and a positive view of the past influenced both past and future life satisfaction. Moreover, less rumination about past negative events (i.e., low score on Past Negative), the tendency to take risks in the present to achieve happy feelings and/or avoid boredom (i.e., high scores on Present Hedonistic), and a less hopeless and pessimistic view about the present (low scores 
on Present Fatalistic) were associated with higher levels of psychological well-being and positive affect. These same time perspective dimensions were associated with lower levels of negative affect. The Future time perspective dimension (i.e., approaching life with selfcontrol, punctuality, and planning for the future) was associated with both psychological wellbeing and positive affect.

Conclusions: High levels of both subjective and psychological well-being are related to a happier and a less sinister past, a more hedonistic and less fatalistic present, as well as to a more structured future. 
2 A Happier and Less Sinister Past, a More Hedonistic and Less Fatalistic Present and a more Structured Future: Time Perspective and Well-Being

$4 \quad U_{t a}$ Sailer ${ }^{1,2}$, Patricia Rosenberg ${ }^{2}$, Ali Al Nima ${ }^{1,2}$, Amelie Gamble ${ }^{1}$, Tommy Gärling ${ }^{1}$, Trevor

5 Archer $^{1,2}$, Danilo Garcia ${ }^{2,3 *}$

${ }^{1}$ Department of Psychology, University of Gothenburg, Göteborg, Sweden

${ }^{2}$ Network for Empowerment and Well-Being, Sweden

$6{ }^{3}$ Center for Ethics, Law and Mental Health (CELAM), University of Gothenburg, Göteborg, 7 Sweden

8 * Correspondence concerning this article should be addressed to D. Garcia, CELAM, University

9 of Gothenburg, Wallinsgatan 8, SE 43141 Mölndal, Sweden. E-mail:

10 danilo.garcia@neuro.gu.se; danilo.garcia@euromail.se. 


\section{Introduction}

12 In order to make sense of them humans anchor events and experiences in time. For example, they

13 may use previous instances of an event to predict its occurrence in the future. Zimbardo and

14 colleagues (e.g., Zimbardo, 2008; Zimbardo \& Boyd, 1999) have developed a model of how

15 people organize and apprehend time. Their time-perspective model consists of five dimensions:

16 (i) Past Positive reflecting a sentimental and positive view of the past; (ii) Past Negative which

17 reflects a pessimistic attitude toward the past; (iii) Present Hedonistic reflecting the desire of

18 experiencing pleasure with slight concern for future consequences; (iv) Present Fatalistic which

19 reflects a lack of hope and control for the future, and; (v) Future which reflects the ability to find

20 reward in achieving specific long-term goals. Time perspective is expected to influence attitudes,

21 behaviour and goals.

22 Empirically it has been shown that time perspective predicts the reported use of alcohol,

23 drug, and tobacco (Keough, Zimbardo \& Boyd, 1999), risky driving (Zimbardo, Keough \& Boyd,

24 1997), indecision and avoidant procrastinations (Diaz-Morales, Ferrari \& Cohen, 2008),

25 environmental engagement (Milfont, Wilson \& Diniz, 2012), the choice of food and of partner,

26 educational achievement, and the distinctness of future goals (Zimbardo \& Boyd 1999). Time

27 perspective is also related to mood. As an example, negative views of the past have been reported

28 to be associated with depression, whereas positive views of the past have been reported to be

29 associated with happiness (Zimbardo \& Boyd 1999; see also Stolarski, Matthews, Postek,

30 Zimbardo \& Bitner, 2013). The influence of a past-oriented time perspective may be explained by

31 that episodic-memory retrieval influences how people imagine and simulate future events

32 (Schacter \& Addis, 2007abc). This view is supported by that the retrieval of past events and the

33 imagination of future events involve overlapping neural regions (Addis, Wong \& Schacter, 2007,

34 Szpunar, Watson \& McDermott, 2007). 
evaluations of her/his life (Diener, Lucas \& Oishi, 2002). It is influenced both by judgments of

37 life satisfaction and fulfillment as well as the balance between the frequency and intensity (or duration) of positive emotions and moods and the frequency and intensity (or duration) of negative emotions and moods. Life-satisfaction judgments are believed to be based on memory of current and previous life experiences that cause evaluative and emotional reactions (Kim-Prieto,

Diener, Tamir, Scollon \& Diener, 2005).

Previous research suggests that subjective well-being may be critically related to time perspective. Thus, Zimbardo and Boyd (1999) proposed that a 'balanced time perspective' is important for optimal functioning. This implies an ability to simultaneously evaluate past, present, and future time perspectives in a flexible manner. In accordance with Zimbardo and Boyd's (1999) assumption, individuals with such a balanced time perspective report larger happiness (Drake, Duncan, Sutherland, Abernethy \& Henry, 2008). Furthermore, subjective wellbeing is higher for individuals with a positive view of the present and past than for individuals with a negative view of the past (Zhang and Howell, 2011). Whereas these studies demonstrate an effect of time perspective on subjective well-being, it is not known whether this effect also depends on the time frame (past, present and future) in which individuals evaluate their well-

52 being. Moreover, life-satisfaction judgments may be interrelated, that is, that past life satisfaction

53 is related to present and future life satisfaction (Kim-Prieto et al., 2005; Garcia, Rosenberg \&

54 Siddiqui, 2011).

Arguing that well-being goes beyond happiness and satisfaction with life, Ryff (1989) proposed the concept of psychological well-being - while subjective well-being focuses on the

57 pursue of happiness and a pleasant life, psychological well-being targets the fulfillment of human 58 potential and a meaningful life even in the face of challenges and adversities (Ryan \& Deci, 59 2001). Psychological well-being is conceptualized as containing six dimensions: self-acceptance 
60 (i.e., the ability to accept all parts of the self), personal growth (i.e., seeing life as an opportunity

61 to develop), purpose in life (i.e., having a sense of meaning in life), environmental mastery (i.e.,

62 the sense of having control in one's life), autonomy (i.e., the sense of self-directedness), and

63 positive relations with others (i.e., the ability of establishing and keeping warmth, close, and

64 trustful relations with others). Thus, psychological well-being has a wider focus on the

65 achievement of full psychological potential and functioning. This concept has still been found to

66 be strongly related to subjective well-being (Compton, Smith, Cornish, \& Qualls, 1996). Urry

67 and colleagues (2004), for example, investigated correlations between individual differences in

68 baseline prefrontal activation and psychological well-being. They found that affect, especially

69 approach-related positive affect (e.g., feeling "interested" or "strong"), is related to

70 psychological well-being (engaging with goal-directed stimuli). Hence, psychological well-being,

71 as well as positive affect, seems to have an orientation towards the future. The concept of

72 approach-related positive affect is, for instance, related to Gray's (1981) Behavioural Activation

73 System or sensitivity to reward as well as approach motivation, while negative affect is related to

74 the Behavioural Inhibition System or sensitivity to punishment as well as avoidance motivation.

75 Moreover, recent research (Garcia, 2013) has found that individuals with high levels of

76 psychological well-being recall more positive than negative memories from the past. How

77 individuals relate to the past may also be related to their own self-acceptance, personal growth,

78 purpose in life, environmental mastery, autonomy, and ability to create positive relations with

79 others.

\section{The present study}

81 Only one study has explored Zimbardo's time perspective model and temporal judgments of life

82 satisfaction (Boniwell, Osin, Linley \& Ivanchenko, 2010). This study used the instrument

83 developed to measure temporal variations of life satisfaction (e.g., Temporal Satisfaction With

84 Life Scale; Pavot, Diener, \& Suh, 1998) that will also be used in the present study. Moreover, the 
85 present study aims to close another knowledge gap in the literature, namely how different time

86 perspective dimensions are related to psychological well-being. Ryff's multidimensional model

87 of psychological well-being is a point of departure in the present study, which although related it

88 is conceptually different to subjective well-being (Kjell, Nima, Sikström, Archer \& Garcia,

89 2013).

90 As detailed in the introduction, temporal satisfaction with life seems to be an interrelated

91 construct, that is, past life satisfaction is related to present and future life satisfaction and vice

92 versa. Thus, the first aim of the present study is to investigate the relationship between the

93 dimensions of time perspective and temporal life satisfaction taking into account the inter-

94 relation between past, present, and future life satisfaction judgments. The second aim is to

95 investigate the relationship between time perspective dimensions and psychological well-being

96 and affect by taking into account the close relationship between psychological well-being and

97 affect, especially positive affect.

98 Method

99 Ethics statement

100 Data collection conformed to the Declaration of Helsinki and the Ethics Committee of the

101 University of Gothenburg approved the research protocol. Verbal informed consent was obtained

102 from all the study participants as agreed by the review board.

\section{Participants and procedure}

104 The data were collected among 400 undergraduate students at an University in the West of

105 Sweden (from which we obtained 324 valid responses corresponding to a $81 \%$ response rate) and

106 at a training facility, a gym complex for weight and aerobic training, in the South of Sweden $(N=$

107158 from which we obtained 129 valid responses corresponding to a $.82 \%$ response rate). The

108 data collected at the training facility was supported by a grant from The Swedish National Centre

109 for Research in Sports (Grant nr. P2012-0097). A total of 453 individuals participated in the study 
110 (148 males and 300 females, 5 who failed to report their gender, mean age 29.74 years $S D=$

11112.86 years). All participants were informed that their participation was voluntary and

112 anonymous. They were presented with a battery of instruments used to collect the relevant

113 measures in the following order: background, time perspective, temporal satisfaction with life,

114 psychological well-being, and affect. Although randomizing the order in which the instruments

115 are presented to participants is suggested to ensure no order effects (Lavrakas, 2008) this was not

116 practically possible to do in both samples. While the university group answered a paper and

117 pencil version of the instruments, the gym group answered an online version by receiving a link

118 to their email addresses and asked to answer the questionnaires in the tranquility of their homes.

119 The gym group also differed in that those who participated received a cinema ticket for their

120 collaboration, whereas no compensation was offered to the undergraduate group.

\section{Measures}

122 Background and Health questionnaire (Karlsson \& Archer, 2007). This instrument was applied to

123 collect background data providing health and health-related information about each participant.

124 The questionnaire consists of items pertaining to age, gender, education, sleeping problems,

125 propensity to perform regular physical exercise, and use of psychotropic drugs.

126 Time Perspective. The Zimbardo Time Perspective Inventory (Zimbardo \& Boyd, 1999)

127 consists of 56 items that measure the following five time dimensions: Past Positive (e.g., "It gives

128 me pleasure to think about my past"), Past Negative (e.g., "I think about the good things that I

129 have missed out on in my life"), Present Hedonistic (e.g., "Taking risks keeps my life from

130 becoming boring"), Present Fatalistic (e.g., "Fate determines much in my life"), and Future (e.g.,

131 "I believe that a person's day should be planned ahead each morning"). The Swedish version has

132 been used and validated in previous studies (Carelli, Wiberg \& Wiberg, 2011; Wiberg, Sircova,

133 Wiberg \& Carelli, 2012) and its psychometric properties validated in many different languages,

134 such as, Portuguese (Milfont, Andrade, Belo \& Pessoa, 2008), Lithuanian (Liniauskaite \& Kairys, 
135 2009), and Spanish (Díaz-Morales, 2006). The Cronbach's $\alpha$ s in the present study were: .81 for

136 Past Positive, .87 for Past Negative, .81 for Present Hedonistic, .68 for Present Fatalistic, and .77 137 for Future.

138 Temporal Life Satisfaction. The Temporal Satisfaction With Life Scale (Pavot, Diener \&

139 Suh, 1998) comprises 15-items rated on a 7-point Likert scale $(1=$ strongly disagree, $7=$ strongly

140 agree) organized in three subscales assessing past (e.g., If I had my past to live over, I would

141 change nothing), present (e.g., I would change nothing about my current life), and future life

142 satisfaction (e.g., There will be nothing that I will want to change about my future). The

143 Cronbach's $\alpha$ in the present study were: .86 for the past subscale, .93 for the present subscale, and 144.88 for the future subscale.

Affect. The Positive Affect and Negative Affect Schedule (Watson, Clark \& Tellegen, 1988) assesses the affective component of subjective well-being by requiring participants to rate on 5-point adjective scales to what extent $(1=$ very slightly, $5=$ extremely $)$ during the last few weeks they experienced 10 positive and 10 negative affect. The positive affect scale includes adjectives such as strong, proud, and interested; and the negative affect scale includes adjectives such as afraid, ashamed, and nervous. The Swedish version has been used in previous studies

151 (e.g., Garcia \& Erlandsson, 2011; Nima, Archer \& Garcia, 2012, 2013; Nima, Rosenberg, Archer 152 \& Garcia, 2013; Schütz, Archer \& Garcia, 2013a, 2014). The Cronbach's $\alpha$ s in the present study 153 were for positive affect .88 and for negative affect .84 . Psychological Well-Being. The Scales of Psychological Well-Being-short version (Clarke,

155 Marshall, Ryff \& Wheaton, 2001) comprises 18 items including 3 items for each of the six 156 dimensions. These dimensions are: self-acceptance (e.g., "I like most aspects of my personality"), 157 personal growth (e.g., "For me, life has been a continuous process of learning, changing, and 158 growth"), purpose in life ("Some people wander aimlessly through life, but I am not one of 159 them”), environmental mastery (e.g., "I am quite good at managing the responsibilities of my 
160 daily life"), autonomy (e.g., "I have confidence in my own opinions, even if they are contrary to

161 the general consensus"), and positive relations with others (e.g., "People would describe me as a

162 giving person, willing to share my time with others"). The Swedish version has been used in

163 previous studies (e.g., Garcia, 2011; Garcia \& Siddiqui, 2009). Since the subscales have been

164 found to have low reliability, the total psychological well-being score (i.e., the sum of the 18

165 items) is recommended as a better and more reliable measure (Garcia \& Siddiqui, 2009). A

166 Cronbach's $\alpha$ of .83 was in the present study obtained for the total psychological well-being

167 score.

168 Statistical treatment

169 In order to determine whether both samples could be pooled, we first conducted an independent

170 t-test between the two groups (undergraduate and gym participants) using the background

171 variables (i.e., education, sleeping problems, exercise frequency, and use of psychotropic drugs)

172 as the dependent variables. We assumed that non-significant differences between the samples in

173 most of these variables would justify pooling them. The results showed that the groups only

174 differed on exercise frequency $(t=4.65, d f=451, p<.001)$, the gym group reporting exercising

175 more frequently $(M=4.06)$ than the undergraduate group $(\mathrm{M}=3.59)$. Since there were no

176 differences in the other variables, all subsequent analyses were conducted on the whole sample

$177(N=453)$.

178 We used the Expectation-Maximization Algorithm (EM-Algorithm) to impute missing

179 values. Little's Chi-Square test for Missing Completely at Random showed a $\chi^{2}=67.25(d f=$

$18053, p=.09)$ for men and $\chi^{2}=77.65(d f=72, p=.31)$ for women. Thus, the EM-Algorithm was

181 suitable to use. Table 1 shows the Pearson's correlations and inter-correlations between all

182 variables. There are significant correlations between many of the variables, which potentially

183 introduces multicollinearity. Thus, the data were analysed using Structural Equation Modeling

184 (SEM) in order to control for error measurement and collinearity among variables. Based on our 
185

186

188

189

190

191

192

193

194

195

196

197

198

199

200

201

202

203

204

205

206 207

research questions we conducted two SEM models, one of the relationship between time perspective and temporal satisfaction (Satisfaction Model) and the other one of the relationship between time perspective and both affect and psychological well-being (PANA and PWB model).

Kurtosis and skewness values for all variables in the first (highest kurtosis value $=.77$; highest skewness value $=-.65$ ) and in the second SEM model (highest kurtosis value .77; highest skewness value .75 ) were within acceptable ranges.

\section{Table 1 should be about here}

The chi-square value was significant for the Satisfaction Model $\left(C h i^{2}=3.96, d f=1, p=\right.$. 047). However, it is known that the chi square statistic is heavily influenced by sample size (Kline 2010) such that larger samples have a higher likelihood of being significant. Since other measures of fit suggested a good model fit (see below), we considered that the Satisfaction Model was acceptable.

The chi-square value for the PANA and PWB Model was strongly significant $\left(C h i^{2}=\right.$ $126.04 d f=3, p<.001)$ suggesting that the model did not fit the data to an acceptable degree. After modifying the model by adding covariances between errors, the chi-square value of the PANA and PWB Model was found to be acceptable $\left(C h i^{2}=3.85, d f=1, p=.05\right)$. Corroborating evidence is provided by the Root Mean Square Error of Approximation fit statistic that was below 0.10 (Satisfaction Model: .08 and PANA and PWB Model: .08) indicating a reasonable fit (Browne \& Cudeck, 1993). The incremental fit index (Bollen, 1989) indicated that the model fit was acceptable (Satisfaction Model: 1.00 and PANA and PWB Model: 1.00). Finally, the BentlerBonett Normed Fit Indices (Bentler \& Bonett, 1980) also indicated that the model fit was acceptable (Satisfaction Model: 1.00 and PANA and PWB Model: 1.00).

\section{Results}


208 The first SEM model was theoretically based on the relationship between the dimensions of

209 temporal life satisfaction (past, present, and future; see Kim-Prieto et al., 2005) and the

210 independency of this construct of subjective well-being (Diener, Lucas \& Oishi, 2002). This first

211 model (Satisfaction Model), was conducted to investigate which time perspective dimensions

212 influence temporal life satisfaction using some modifications (i.e., regression weights from past

213 life satisfaction to present life satisfaction and from present life satisfaction to future life

214 satisfaction) to obtain a better fitting for this model. The second model was based on the relation

215 between affectivity measured by the Positive Affect and Negative Affect Schedule and

216 psychological well-being (Urry et al., 2004). This model (PANA and PWB Model) was

217 conducted to investigate which perspective dimensions influence affect and psychological well-

218 being. The possible covariances for the five time perspective dimensions are taken into account in

219 both models.

220

The results of the Satisfaction Model showed that the Past Positive $(\beta=.38, p<.001)$

221 time perspective dimension predicted past life satisfaction, while the Past Negative dimension

222 significantly counterpredicted past life satisfaction $(\beta=-.49, p=<.001)$. Present life satisfaction

223 was predicted by the Present Hedonistic $(\beta=.14, p<.001)$ and counterpredicted by the Past

224 Negative $(\beta=-.38, p<.001)$ time perspective dimensions. Present life satisfaction was also

225 predicted by past life satisfaction $(\beta=.17, p=.002)$. Future life satisfaction was predicted by the

226 Past Positive $(\beta=.12, p=.005)$, the Present Hedonistic $(\beta=.11, p=.007)$, and the Future $(\beta=$.

$22709, p=.03$ ) time perspective dimensions. Present life satisfaction was also involved in the

228 prediction of future life satisfaction $(\beta=.43, p<.001)$, while the Past Negative dimension

229 counterpredicted future life satisfaction $(\beta=-.12, p=.020)$. The whole model yielded a $R^{2}=.31$

230 for past life satisfaction, .33 for present life satisfaction, and .33 for future life satisfaction. See

231 Figure 1 and Table 2 for the details. 
234 the Present Hedonistic $(\beta=.28, p<.001)$, and the Future $(\beta=.23, p<.001)$ time perspective

235 dimensions, while the Past Negative $(\beta=-.22, p<.001)$ and the Present Fatalistic $(\beta=-.24, p<$.

236 001) dimensions counterpredicted positive affect. Negative affect was predicted by the Past

237 Negative $(\beta=.53, p<.001)$ and the Present Fatalistic $(\beta=.09, p=.03)$ time perspective

238 dimensions, while the Present Hedonistic $(\beta=-.10, p=.01)$ dimension counterpredicted negative

239 affect. The whole model yielded a $R^{2}=.25$ for positive affect and .36 for negative affect. See

240 Figure 2 and Table 2 for the details. The results of this model also showed that psychological

241 well-being was predicted by all five time perspective dimensions. Specifically, the Past Positive

$242(\beta=.20, p<.001)$, the Present Hedonistic $(\beta=.21, p<.001)$, and the Future $(\beta=.09, p=.010)$

243 time perspective dimensions, while the Past Negative $(\beta=-.43, p<.001)$ and the Present

244 Fatalistic $(\beta=-.24, p<.001)$ dimensions counterpredicted psychological well-being. The whole

245 model showed an $R^{2}=.46$ for psychological well-being. See Figure 2 and Table 2 for the details.

\section{Figure 2 should be about here}

Table 2 should be about here

Since the results suggested that past positive and past negative time perspective contributed differently to psychological well-being, the two correlation coefficients $(.41$ and -.58$)$ were Fisher-transformed and then compared with each other using a z-test (Steiger 1980). This analysis was performed in order to investigate which of the correlations was stronger. The

252 correlation between past negative and psychological well-being was found to be significantly

253 higher than that for past positive and psychological well-being $(z=17.43, \mathrm{p}<.001)$.

\section{Discussion}


The aim of the present study was to investigate the relationship between time perspective

256

257

258

259

260

261

262

263

264

265

266

267

268

269

270

271

272

273

274

275

276

277

278

dimensions and temporal satisfaction with life, affect, and psychological well-being. As expected, satisfaction with past life was related to past perspective (i.e., Past Positive and Past Negative).

This is understandable since individuals who report feeling pleasure, nostalgia, and happiness when recalling the past (i.e., Past Positive) should report feeling more satisfied with their past life. Likewise, rumination of bad moments from the past and generalization of bad past outcomes to the present and to the self (i.e., Past Negative) ought to predict lower satisfaction with the past. This is, for instance, related to research on explanatory style —individuals who internalize and interpret past negative events as long-lasting and associated to all aspects of their life are prone to depression (Buchanan \& Seligman, 1995). Present life satisfaction was predicted by the tendency to take risks in order to achieve more positive emotions or avoid boredom in the present (i.e., Present Hedonistic). Consistent with previous suggestions (Kim-Prieto et al., 2005; Garcia et al., 2011), present life satisfaction was predicted by how one feels with the past. Satisfaction with the future was, also as expected, predicted by the tendency to plan for the future, goal-setting, punctuality, and meeting deadlines (i.e., the Future time perspective dimension). As in previous studies (Garcia et al., 2011; Pavot et al., 1998), future life satisfaction was also related to individuals' view of the past and the present. However, whereas the view of the past influenced satisfaction also in the present and future, the Present Hedonistic dimension did not influence the view of the past. This suggests that the Present Hedonistic dimension expresses a "here and now" approach to life.

In sum, the Past Negative time perspective dimension predicted lower levels of temporal life satisfaction as a whole, the Past Positive time perspective dimension predicted both past and future life satisfaction, and the Present Hedonistic time perspective dimension predicted both present and future life satisfaction (see Figure 3). Our findings extend previous results concerning 
279 the relationships between time perspectives and subjective well-being (e.g., Boniwell et al.

280 2010) by specifying in which time frame life satisfaction is evaluated.

Figure 3 should be about here

We also found that frequently feeling proud, interested, and engaged (i.e. positive affect)

was associated with the tendency to take risks in order to achieve more positive emotions or

avoid boredom in the present (i.e., the Present Hedonistic time perspective dimension), and

approaching behavior related to the Future time perspective dimension. This is in line with

suggestions (Sirois, 2014) with regard to the other end of this affect dimension and its relation to

procrastination, namely, low positive affect's role in the explanation of why procrastination is

associated to less focus on the future. Positive affect, as measured here, is indeed labeled as high

activation affect (Russell \& Carroll, 1999). Accordingly, Schütz and colleagues (2013b) showed

that agentic behavior (i.e., goal-setting, planning for the future, self-control, etcetera) is

associated with a self-fulfilling state defined as frequently experiencing high activation positive

affect and infrequently experiencing high activation negative affect (see also Garcia, Anckarsäter

293 \& Lundström, 2013). In contrast, the Past Negative and the Present Fatalistic time perspective

294 dimensions attenuated positive affect. In other words, having a negative view of the past (i.e.,

295 Past Negative) and feeling hopeless and lacking control were associated with experiencing few

296 positive emotions. Moreover, a negative view of the past (i.e., Past Negative) and present

297 (Present Fatalistic) predicted frequently feeling afraid, nervous and irritated, while a hedonistic

298 present perspective (i.e., Present Hedonistic) attenuated these negative emotions.

Finally, psychological well-being was predicted by all time perspective dimensions.

300 Memories of the past as being happy (i.e., Past Positive), taking risks in the present in order to

301 achieve happy feelings and/or avoid boredom (i.e., Present Hedonistic), and a Future time

302 perspective associated to agentic values (i.e., goal-setting, self-control, planning for the future,

303 etcetera) were associated with higher levels of psychological well-being. In contrast, ruminating 
304 about negative events (i.e., Past Negative) and a hopeless and pessimistic view about the present

305 (Present Fatalistic) was associated with low levels of psychological well-being. Interestingly, the

306 effect of a Past Negative time perspective on psychological well-being was stronger than the

307 effect of a Past Positive time perspective, thus supporting the view that the psychological effects

308 of negative events are stronger than those of positive events (Baumeister, Catanese \& Vohs,

309 2001). Along these lines, whereas a positive view of the past influenced past and future life

310 satisfaction as well as psychological well-being, the effect of a negative view of the past

311 influenced a larger number of variables - in fact on all variables tested. Past Negative affected

312 life satisfaction in all time frames, positive affect, negative affect and psychological well-being.

313 This suggest that in order to improve general well-being, it may be more effective to reduce a

314 Past Negative time perspective than by inducing a Past Positive time perspective. To summarize

315 the results of the second model, Past Negative, Present Hedonistic, and Present Fatalistic time

316 perspectives were related to affect and psychological well-being. The Future time perspective

317 was related to both positive affect and psychological well-being, while the Past Positive time

318 perspective only predicted psychological well-being (see Figure 4).

Figure 4 should be about here

\section{Limitations and suggestions for future research}

321 The present study used self-reports which does not allow us to infer whether or not time

322 perspective causally predicts actual well-being. Ryff's multidimensional approach is, for instance,

323 suggested to describe the fully functional individual (Ryff \& Keyes, 1995). Thus, a balanced time

324 perspective (i.e., the ability to hold past, present, and future time perspectives at the same time

325 and to use them flexibly) may be caused by individuals' tendency to accept all parts of her/his

326 personality (i.e., high self-acceptance), see life as an opportunity to develop (i.e., personal

327 growth), have a sense of meaning in life (i.e., purpose in life), have control in life (i.e.,

328 environmental mastery), have autonomy, and establish and keep positive relations with others. 
329 Another limitation is the fixed order in which the questionnaires were administered, after all,

330 randomization of the order in which the instruments are presented to participants is suggested to

331 ensure that responses to survey questions are not affected by the order of the instruments

332 (Lavrakas, 2008). Also, we used the total psychological well-being score instead of each of the

333 subscales because the short version used here has been found to have low reliability in previous

334 studies (e.g., Clark et al., 2001, Garcia \& Siddiqui, 2009). A more reliable version may help

335 disentangle which time perspective is associated with each psychological well-being dimension.

336 Concluding remarks

337 High levels of both subjective and psychological well-being were found to be related to

338 memories of a happier and less sinister past, a more hedonistic and less pessimistic present, as

339 well as to a more structured future.

340 "Happiness can be found, even in the darkest of times,

341 if one only remembers to turn on the light"

342 Albus Dumbledore in Harry Potter and the Prisoner of Azkaban

\section{Acknowledgements}

344 We would like to thank Björn Mikmar and his most helpful staff at Friskis\&Svettis

345 Karlskrona/Ronneby for their collaboration in the collection of the data. We would also like to

346 convey our gratitude to the participants for spending their valuable time answering to the

347 questionnaires, to Erik Lindskär for his help with the data collection, and to Nabeel Abd

348 Algafoor at the University of Mustansiryah, Bagdad, for his statistical advice. Last but not the

349 least we want to thank Sophia Isabella Garcia Rosenberg for her help with Figures 3 and 4. 
350 References

351 Addis, D. R., Wong, A. T., \& Schacter, D. L. (2007). Remembering the past and imagining the 352 future: Common and distinct neural substrates during event construction and elaboration. 353 Neuropsychologia, 45, 1363-1377.

354 Baumeister, R.F., Catanese, K.R., \& Vohs, K.D. (2001). Bad is stronger than good. Review of 355 General Psychology, 5, 323-370. 
Bentler, P. M., \& Bonnet, D. C. (1980). Significance Tests and Goodness of Fit in the Analysis of Covariance. Structures. Psychological Bulletin, 88, 588-606.

Bollen, K.A. (1989), Structural Equations with Latent Variables, New York: John Wiley \& Sons, Inc.

Boniwell, I., Osin, E., Linley, P. A., \& Ivanchenko, G. V. (2010). A question of balance: Time perspective and well-being in British and Russian samples. The Journal of Positive Psychology: Dedicated to furthering research and promoting good practice, 5, 24-40.

Browne, M. W., \& Cudeck, R. (1993). Alternative ways of assessing model fit. In K. A. Bollen, \& J. S. Long (Eds.), Testing Structural Equation Models (pp. 136-162). Newbury Park, CA: Sage.

Buchanan, G., M., \& Seligman, M. E. P. (1995). Explanatory Style. Hillsdale, NJ: Erlbaum.

Carelli, M. G., Wiberg, B., \& Wiberg, M. (2011). Development and construct validation of the Swedish Zimbardo Time Perspective Inventory. European Journal of Psychological Assessment, 27, 220-227.

Clarke, P. J., Marshall, V. M., Ryff, C. D., \& Wheaton, B. (2001). Measuring psychological wellbeing in the Canadian study of health and aging. International Psychogeriatrics, 13, 7990.

Compton, W. C., Smith, M. L., Cornish, K. A., \& Qualls, D. L. (1996). Factor structure of mental health measures. Journal of Personality and Social Psychology, 71, 406-413.

Díaz-Morales, J. F. (2006). Estructura factorial y fiabilidad del Inventario de Perspective Temporal de Zimbardo. Psicothema, 18, 565-567.

Díaz-Morales, J. F., Ferrari, J. R., \& Cohen, J. R. (2008). Indecision and avoidant procrastination: The role of morningness-eveningness and time perspective in chronic delay lifestyles. Journal of General Psychology, 135, 228-240. 
380

381

382

383

384

385

386

387

388

389

390

391

392

393

394

395

396

397

398

399

400

401

402

403

Diener, E., Lucas, R. E. , \& Oishi, S. (2002). Subjective well-being: The science of happiness and life satisfaction. In C.R. Snyder \& S.J. Lopez (Ed.), Handbook of Positive Psychology. Oxford and New York: Oxford University Press.

Drake, L., Duncan, E., Sutherland, F., Abernethy, C., \& Henry, C. (2008). Time Perspective and Correlates of Well-Being. Time and Society, 17, 47-61.

Garcia, D (2011). Two Models of Personality and Well-Being among Adolescents. Personality and Individual Differences, 50, 1208-1212. DOI: 10.1016/j.paid.2011.02.009.

Garcia, D. (2013). La vie en Rose: High Levels of Well-Being and Events Inside and Outside Autobiographical Memory. Journal of Happiness Studies. DOI: 10.1007/s10902-0139443-x.

Garcia, D., Anckarsäter, H., \& Lundström, S. (2013). Self-directedness and Cooperativeness, Psychosocial Dysfunction and Suffering in ESSENCE. The Scientific World Journal. DOI: $10.1155 / 2013 / 416981$.

Garcia, D., \& Erlandsson, A. (2011). The Relationship between Personality and Subjective WellBeing: Different Association Patterns when Measuring the Affective Component in Frequency and Intensity. Journal of Happiness Studies, 12, 1023-1034. DOI: 10.1007/s10902-010-9242-6.

Garcia, D., Rosenberg, P., \& Siddiqui, A. (2011). Tomorrow I Could Be in Trouble...But The Sun Will Come Out Next Year: The Effect of Temporal Distance on Adolescents' Judgments of Life Satisfaction. Journal of Adolescence, 34, 751-757. DOI: 10.1016/j.adolescence.2010.08.006.

Garcia, D, \& Siddiqui, A. (2009). Adolescents' Psychological Well-Being and Memory for Life Events: Influences on Life Satisfaction with Respect to Temperamental Dispositions. Journal of Happiness Studies, 10,387 - 503. DOI: 10.1007/s10902-008-9096-3. 
404 Gray, J. A. (1981). A critique of Eysenck's theory of personality, In H. J. Eysenck (Ed.) A model 405 for personality. Springer: Berlin.

406 Karlsson, E., \& Archer, T. (2007). Relationship between personality characteristics and affect: 407 Gender and affective personality. Individ- ual Differences Research, 5, 44-58.

408 Keough, K.A., Zimbardo, P.G., \& Boyd, J.N. (1999). Who's smoking, drinking and using drugs? 409 Time perspective as a predictor of substance use. Basic and Applied Social Psychology, $410 \quad 21,149-164$.

411 Kim-Prieto, C., Diener, E., Tamir, M., Scollon, C. N., \& Diener, M. (2005). Integrating the 412 Diverse Definitions of Happiness: A Time-Sequential Framework of Subjective WellBeing. Journal of Happiness Studies, 6, 261 - 300.

Kjell, O. N. E., Nima, A. A., Sikström, S., Archer, T., \& Garcia, D. (2013). Iranian and Swedish 415 Adolescents: Differences in Personality Traits and Well-Being. PeerJ 1:e197. DOI: 10.7717/peerj.197. Guilford Press

Lavrakas, P. J. (2008). Encyclopedia of Survey Research Methods. Sage: London.

420 Liniauskaite, A., \& Kairys, A. (2009). The Lithuanian version of the Zimbardo Time Perspective 421 Inventory (ZTPI). Psichologija, 40, 66-87.

422 Milfont, T. L., Andrade, P. R., Belo, R. P., Pessoa, V. S. (2008). Testing Zimbardo Time 423 Perspective Inventory in a Brazilian sample. Interamerican Journal of Psychology, 42, 424 49-58.

425 Milfont, T. L., Wilson, J., \& Diniz, P. (2012). Time Perspective and environmental engagement: A 426 meta-analysis. International Journal of Psychology, 47, 325-334. 
427 Nima, A. A., Archer, T., \& Garcia, D. (2012). Adolescents' happiness-increasing Strategies, 428 Temperament, and Character: Mediation models on Subjective Well-Being. Health, 4, 429 802-810. DOI: 10.4236/health.2012.410124.

430 Nima, A. A., Archer, T., \& Garcia, D. (2013). The Happiness-Increasing Strategies Scales in a $431 \quad$ Sample of Swedish Adolescents. International Journal of Happiness and Development, 1, $432 \quad 196-211$.

433 Nima, A. A., Rosenberg, P., Archer, T., \& Garcia, D. (2013). Anxiety, Affect, Self-Esteem, and 434 Stress: Mediation and Moderation Effects on Depression. PLoS ONE 8(9): e73265. DOI:10.1371/journal.pone.0073265.

Pavot, W., Diener, E., \& Suh, E. (1998). The temporal satisfaction with life scale.Journal of Personality Assessment, 2, 340-354.

Russell, J. A., \& Carroll, J. M. (1999). On the bipolarity of positive and negative affect. Psychological Bulletin, 125, 3-30.

Ryan, R. M., \& Deci, E. L. (2001). On happiness and human potentials: A review of research on 441 hedonic and eudaimonic well-being. Annual Review of Psychology, 52, 141-166.

Ryff, C.D. (1989). Happiness is everything, or is it? Explorations on the meaning of psychological well-being. Journal of Personality and Social Psychology, 57, 1069-1081.

Ryff, C. D., \& Keyes, C. L. (1995). The structure of psychological well-being revisited. Journal 445 of Personality and Social Psychology, 69, 719-727.

446 Schacter, D. L., \& Addis, D. R. (2007a). The cognitive neuroscience of constructive memory: Remembering the past and imagining the future. Philosophical Transactions of the Royal

449 Schacter, D. L., \& Addis, D. R. (2007b). The ghosts of past and future. Nature, 445, 27.

450 Schacter, D. L., \& Addis, D. R. (2007c). On the constructive episodic simulation of past and 451 future events. Behavioral and Brain Sciences, 30, 331-332. 
452 Schütz, E., Archer, T. \& Garcia, D. (2013a). Character Profiles and Adolescents' Self-reported 453 Happiness. Personality and Individual Differences, 54, 841-844. DOI: 10.1016/j.paid.2012.12.020.

455

456

457

458

459

460

461

462

463

464

465

466

467

468

469

470

471

472

473

474

475

476

Schütz, E., Garcia, D., \& Archer, T. (2014). Affective State, Stress, and Type A-personality as a Function of Gender and Affective Profiles. International Journal of Research Studies in Psychology, 3, 51-64. DOI: 10.5861/ijrsp.2013.450

Schütz, E., Sailer, U., Nima, A., Rosenberg, P., Andersson Arntén, A-C., Archer, T., \& Garcia, D. (2013b). The affective profiles in the USA: happiness, depression, life satisfaction, and happiness- increasing strategies. PeerJ 1:e156. DOI 10.7717/peerj.156.

Sirois, F. M. (2014). Out of sight, out of time? A meta-analytic investigation of procrastination and time perspective. European Journal of Personality. DOI: 10.1002/per.1947.

Steiger, J. H. (1980). Tests for comparing elements of a correlation matrix. Psychological Bulletin, 87, 245-251.

Stolarski, M., Matthews, G., Postek, S., Zimbardo, P. G., \& Bitner, J. (2013). How we feel is a matter of time: Relationships between time perspective and mood. Journal of Happiness Studies. DOI 10.1007/s10902-013-9450-y.

Szpunar, K. K., Watson, J. M., \& McDermott, K. B. (2007). Neural substrates of envisioning the future. Proceedings of the National Academy of Sciences of the United States of America, 104, 642-647. doi:10.1073/pnas.0610082104

Urry, H. L., Nitschke, J. B., Dolski, I., Jackson, D. C., Dalton, K. M., Mueller, C. J., et al. (2004). Making life worth living: Neural correlates of well-being. Psychological Science, 15, 367-372.

Watson, D., Clark, L. A., \& Tellegen, A. (1988). Development and validation of brief measures of positive and negative affect: The PANAS scales. Journal of Personality and Social 
477 Wiberg, M., Sircova, A., Wiberg, B., \& Carelli, M. G. (2012). Operationalizing Balanced Time

$478 \quad$ Perspective in a Swedish Sample. The International Journal of Educational and

$479 \quad$ Psychological Assessment, 12, 95-107.

480 Zhang, J., \& Howell, R. T. (2011). Do time perspectives predict unique variance in life

$481 \quad$ satisfaction beyond personality traits? Personality and Individual Differences, 50, 1261-

$482 \quad 1266$.

483 Zimbardo, P.G. (2008). The time paradox: The new psychology of time that will change your life.

$484 \quad$ New York: Free Press.

485 Zimbardo, P.G., \& Boyd, J.N. (1999). Putting time in perspective: A valid, reliable individual486 differences metric. Journal of Personality and Social psychology, 77, 1271-1288.

487 Zimbardo, P.G., Keough, K.A., \& Boyd, J.N. (1997). Present time perspective as a predictor of $488 \quad$ risky driving. Personality and Individual Differences, 23, 1007-1023.

\section{Legends}

490 Table 1. Correlations between Time Perspective, Subjective and Psychological Well-Being

491 variables.

492 Table 2. Standardized and unstandardized coefficients for both models in the study.

493 Figure 1. Structural equation model of time perspective and temporal life satisfaction (i.e., the

494 Satisfaction Model). Showing all inter-correlations for the five time perspective dimensions, all 495 paths from the time perspective dimensions to the three temporal life satisfaction constructs, and 496 their standardized parameter estimates. Chi-square $=3.96, d f=1, p=.047$; comparative fit index $=$ $4971.00 ;$ incremental fit index $=1.00 ;$ normed fit index $=1.00 ;$ root mean square error of 498 approximation $=0.08$.

499 Figure 2. Structural equation model of time perspective, psychological well-being and affect (i.e., 500 the PWB and PANA Model). Showing all inter-correlations for the five time perspective 
501 dimensions, all paths from the time perspective dimensions to psychological well-being, positive

502 affect, and negative affect, and their standardized parameter estimates. Chi-square $=3.85, d f=1, p$

$503=.05 ;$ comparative fit index $=1.00 ;$ incremental fit index $=1.00 ;$ normed fit index $=1.00 ;$ root

504 mean square error of approximation $=0.08$.

505 Figure 3. Summary of the results with regard to the relationships between the different time

506 perspectives and temporal life satisfaction dimensions.

507 Figure 4. Summary of the results with regard to the relationships between the different time

508 perspectives, psychological well-being, and affect. 


\section{Table 1 (on next page)}

Table 1. Correlations between Time Perspective, Subjective and Psychological WellBeing variables. 
Table 1. Correlations between Time Perspective, Subjective and Psychological Well-Being variables.

\begin{tabular}{|c|c|c|c|c|c|c|c|c|c|c|c|}
\hline+ & 1 & 2 & 3 & 4 & 5 & 6 & 7 & 8 & 9 & 10 & 11 \\
\hline Past Positive (1) & - & & & & & & & & & & \\
\hline Past Negative (2) & $-.39^{* *}$ & - & & & & & & & & & \\
\hline Present Hedonistic (3) & $.13^{* *}$ & .05 & - & & & & & & & & \\
\hline Present Fatalistic (4) & -.07 & $.37^{* *}$ & $.24^{* *}$ & - & & & & & & & \\
\hline Future (5) & .01 & .03 & $-.22^{* *}$ & $-.15^{* *}$ & - & & & & & & \\
\hline Past Satisfaction with Life (面) & $.58^{* *}$ & $-.63^{* *}$ & .07 & $-.17^{* *}$ &,- 03 & - & & & & & \\
\hline Present Satisfaction with Life (7) & $.30^{* *}$ & $-.52^{* *}$ & $.12^{*}$ & $-.20^{* *}$ &,- 02 & $.45^{* *}$ & - & & & & \\
\hline Future Satisfaction with Lifg (8) & $.31^{* *}$ & $-.36^{* *}$ & $.17^{* *}$ & -.08 & 05 & $.39^{* *}$ & $.53^{* *}$ & - & & & \\
\hline Positive Affect (9) & $.23^{* *}$ & $-.32^{* *}$ & $.17^{* *}$ & $-.30^{* *}$ & $19^{* *}$ & $.24^{* *}$ & $.53^{* *}$ & $.40^{* *}$ & - & & \\
\hline Negative Affect (10) & $-.29^{* *}$ & $.58^{* *}$ & -.07 & $.27^{* *}$ & .04 & $-.43^{* *}$ & $-.49^{* *}$ & $-.39^{* *}$ & $-.29^{* *}$ & - & \\
\hline Psychological Well-Being 11) & $.41^{* *}$ & $-.58^{* *}$ & $.14^{* *}$ & $-.38^{* *}$ & .07 & $.49^{* *}$ & $.59^{* *}$ & $.47^{* *}$ & $.53^{* *}$ & $-.60^{* *}$ & - \\
\hline
\end{tabular}




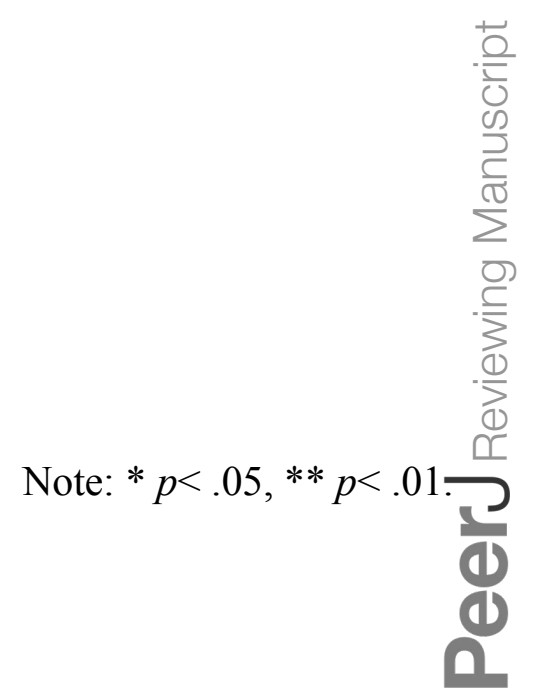




\section{Figure 1}

Figure 1. Structural equation model of time perspective and temporal life satisfaction (i.e., the Satisfaction Model).

Showing all inter-correlations for the five time perspective dimensions, all paths from the time perspective dimensions to the three temporal life satisfaction constructs, and their standardized parameter estimates. Chi-square $=3.96, d f=1, p=.047$; comparative fit index $=$ 1.00; incremental fit index $=1.00$; normed fit index $=1.00$; root mean square error of approximation $=0.08$. 


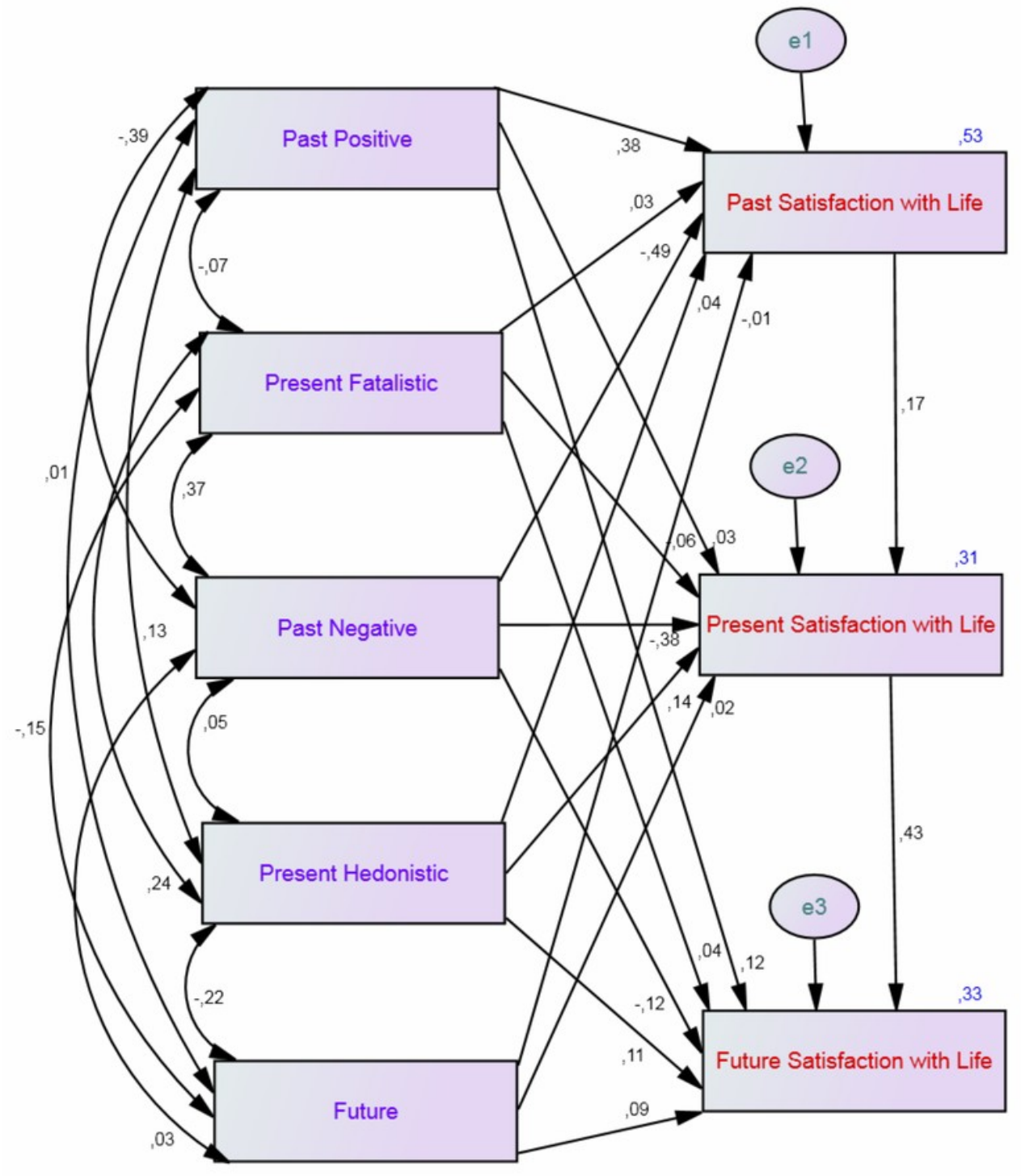




\section{Figure 2}

Figure 2. Structural equation model of time perspective, psychological well-being and affect (i.e., the PWB and PANA Model).

Showing all inter-correlations for the five time perspective dimensions, all paths from the time perspective dimensions to psychological well-being, positive affect, and negative affect, and their standardized parameter estimates. Chi-square $=3.85, d f=1, p=.05$; comparative fit index $=1.00$; incremental fit index $=1.00 ;$ normed fit index $=1.00$; root mean square error of approximation $=0.08$. 


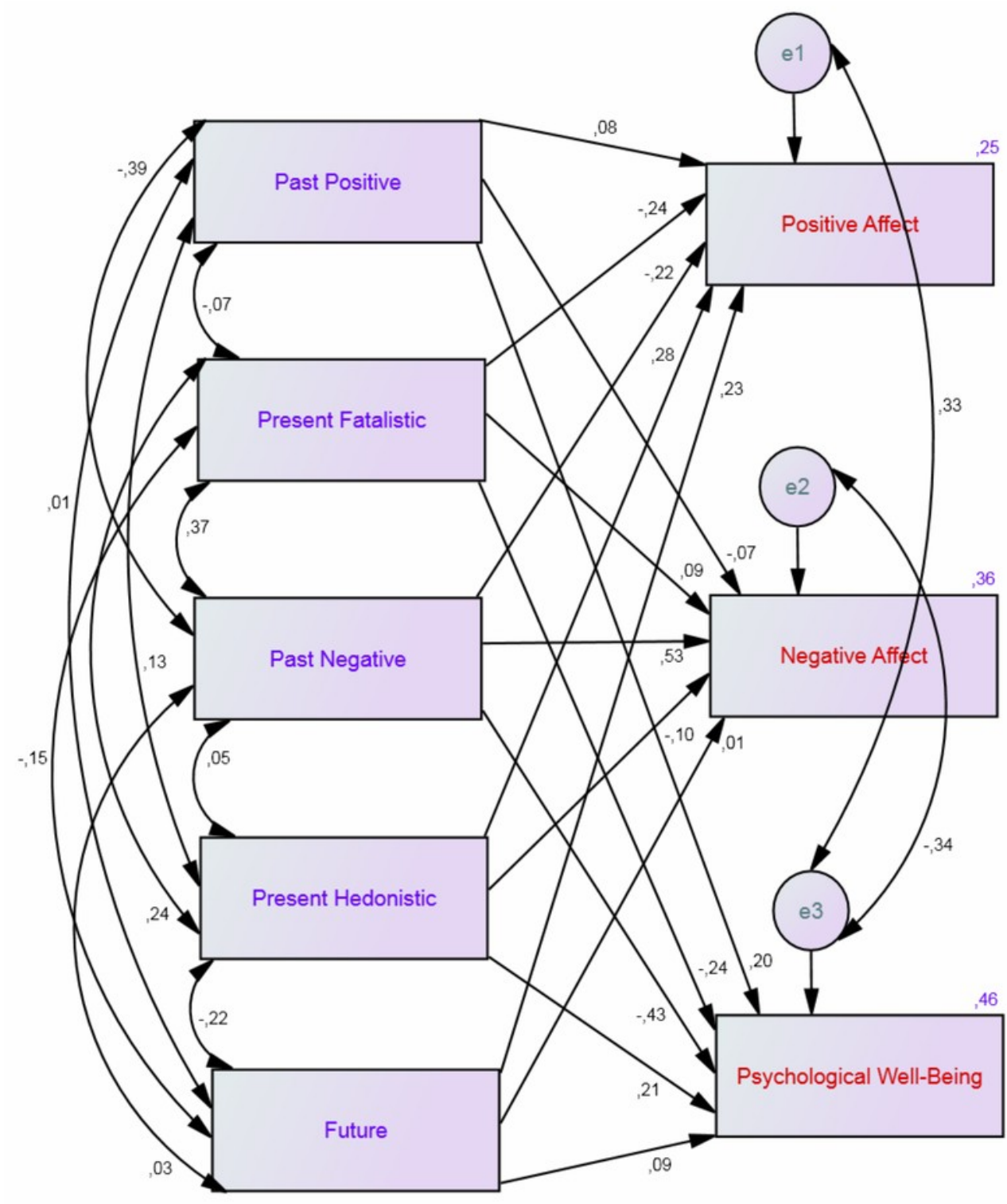




\section{Figure 3}

Figure 3. Summary of the results with regard to the relationships between the different time perspectives and temporal life satisfaction dimensions.

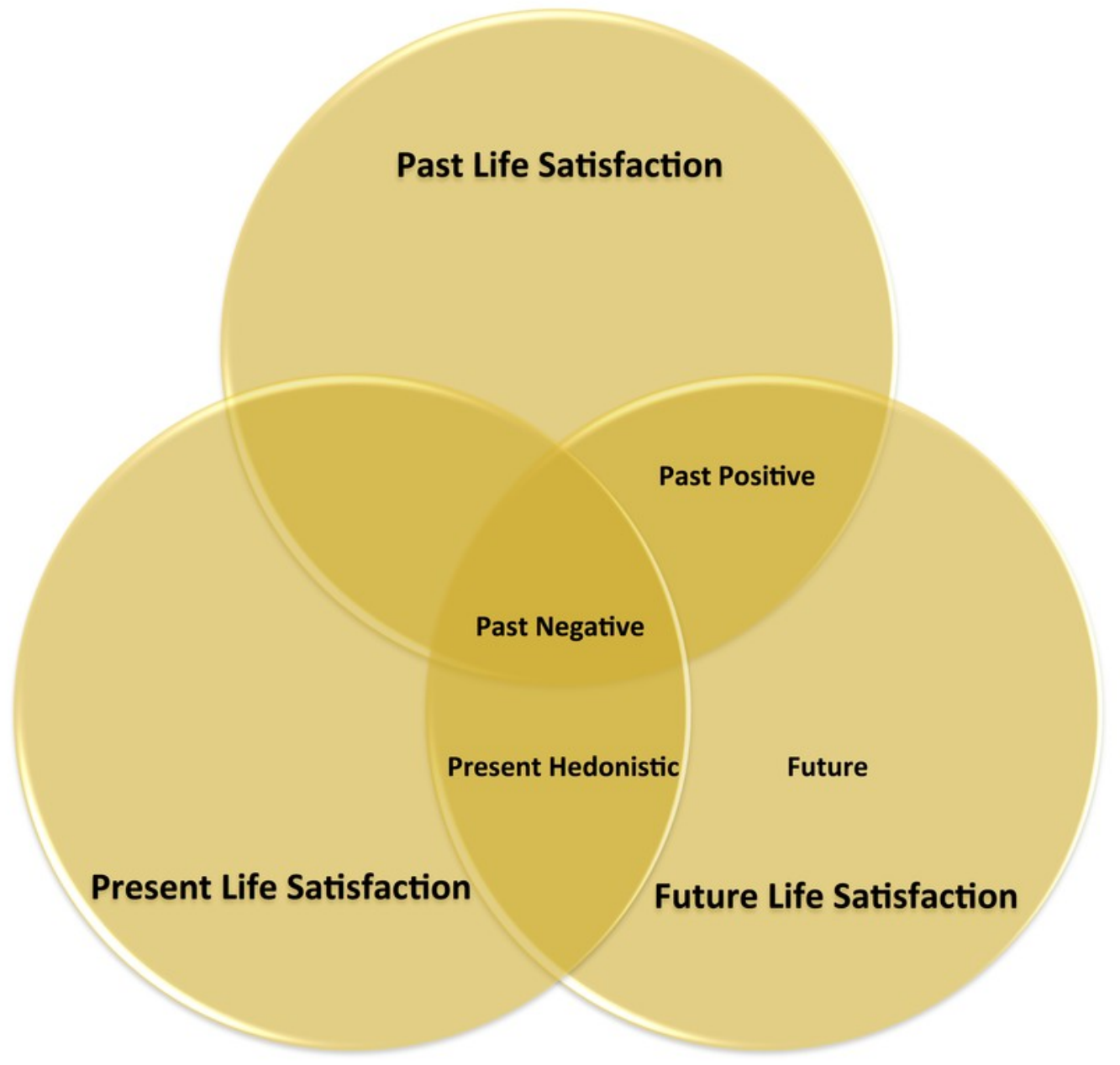




\section{Table 2 (on next page)}

Table 2. Standardized and unstandardized coefficients for both models in the study. 
Table 2. Standardized and unstandardized coefficients for both models in the study.

\begin{tabular}{|c|c|c|c|c|c|c|}
\hline $\begin{array}{c}\text { Time Perspective } \\
\text { dimension }\end{array}$ & Well-Being Measure & $R^{2}$ & $\beta$ & $B$ & $S E$ & $p$ \\
\hline \multicolumn{7}{|c|}{$\underline{\text { Satisfaction Model }}$} \\
\hline Past Positive & \multirow{5}{*}{ Past Life Satisfaction } & \multirow{5}{*}{.53} & .38 & .82 & .08 & $<.001$ \\
\hline Past Negative & & & -.49 & -.91 & .07 & $<.001$ \\
\hline Present Hedonistic & & & .04 & .11 & .10 & .28 \\
\hline Present Fatalistic & & & .03 & .82 & .10 & .43 \\
\hline Future & & & -.01 & -.03 & .10 & .78 \\
\hline Past Positive & \multirow{5}{*}{ Present Life Satisfaction } & \multirow{5}{*}{.31} & .03 & .06 & .11 & .56 \\
\hline Past Negative & & & -.38 & -.73 & .10 & $<.001$ \\
\hline Present Hedonistic & & & .14 & .43 & .13 & $<.001$ \\
\hline Present Fatalistic & & & -.06 & -.17 & .13 & .19 \\
\hline Future & & & .02 & .06 & .12 & .65 \\
\hline Past Positive & \multirow{5}{*}{ Future Life Satisfaction } & \multirow{5}{*}{.33} & .12 & .22 & .08 & .005 \\
\hline Past Negative & & & -.12 & -.18 & .08 & .02 \\
\hline Present Hedonistic & & & .11 & .28 & .10 & .007 \\
\hline Present Fatalistic & & & .04 & .10 & .03 & .31 \\
\hline Future & & & .09 & .22 & .10 & .03 \\
\hline \multicolumn{7}{|c|}{ PANA and PWB Model } \\
\hline Past Positive & \multirow{5}{*}{ Positive Affect } & \multirow{5}{*}{.25} & .08 & .08 & .04 & .06 \\
\hline Past Negative & & & -.22 & -.17 & .04 & $<.001$ \\
\hline Present Hedonistic & & & .28 & .36 & .06 & $<.001$ \\
\hline Present Fatalistic & & & -.24 & -.30 & .06 & $<.001$ \\
\hline Future & & & .23 & .29 & .05 & $<.001$ \\
\hline Past Positive & \multirow{5}{*}{ Negative Affect } & \multirow{5}{*}{.36} & -.07 & -.06 & .04 & .11 \\
\hline Past Negative & & & .53 & .39 & .03 & $<.001$ \\
\hline Present Hedonistic & & & -.10 & -.12 & .05 & .01 \\
\hline Present Fatalistic & & & .09 & .10 & .05 & .03 \\
\hline Future & & & .01 & .02 & .05 & .73 \\
\hline Past Positive & \multirow{5}{*}{$\begin{array}{l}\text { Psychological } \\
\text { Well-Being }\end{array}$} & \multirow{5}{*}{.46} & .20 & .17 & .03 & $<.001$ \\
\hline Past Negative & & & -.43 & -.31 & .03 & $<.001$ \\
\hline Present Hedonistic & & & .21 & .25 & .04 & $<.001$ \\
\hline Present Fatalistic & & & -.24 & -.27 & .04 & $<.001$ \\
\hline Future & & & .09 & .10 & .04 & .01 \\
\hline
\end{tabular}

Note: Significant relations in bold type. 


\section{Figure 4}

Figure 4. Summary of the results with regard to the relationships between the different time perspectives, psychological well-being, and affect.

\section{Psychological Well-Being}

Past Positive

Future

Past Negative

Present Hedonistic

Present Fatalistic

Positive Affect Negative Affect 